NBER WORKING PAPER SERIES

\title{
SOME INTERNATIONAL EVIDENCE FOR KEYNESIAN ECONOMICS WITHOUT THE PHILLIPS CURVE
}

\author{
Roger Farmer \\ Giovanni Nicolò \\ Working Paper 25743 \\ http://www.nber.org/papers/w25743 \\ NATIONAL BUREAU OF ECONOMIC RESEARCH \\ 1050 Massachusetts Avenue \\ Cambridge, MA 02138 \\ April 2019, Revised June 2019
}

We thank George Bratsiotis for inviting us to present this paper at the 9th annual conference organized by the Centre of Growth and Economic Business Cycles at the University of Manchester on July 5th-6th 2018. The views expressed in this paper are those of the authors and do not necessarily reflect the views of the Federal Reserve Board, the Federal Reserve System, or the National Bureau of Economic Research.

NBER working papers are circulated for discussion and comment purposes. They have not been peer-reviewed or been subject to the review by the NBER Board of Directors that accompanies official NBER publications.

(C) 2019 by Roger Farmer and Giovanni Nicolò. All rights reserved. Short sections of text, not to exceed two paragraphs, may be quoted without explicit permission provided that full credit, including $(\odot$ notice, is given to the source. 
Some International Evidence for Keynesian Economics without the Phillips Curve Roger Farmer and Giovanni Nicolò

NBER Working Paper No. 25743

April 2019, Revised June 2019

JEL No. E3,E4,F0

\begin{abstract}
$\underline{\text { ABSTRACT }}$
Farmer and Nicolò (2018) show that the Farmer Monetary (FM)- model outperforms the threeequation New-Keynesian (NK)-model in post war U.S. data. In this paper, we compare the marginal data density of the FM-model with marginal data densities for determinate and indeterminate versions of the NK-model for three separate samples using U.S., U.K. and Canadian data. We estimate versions of both models that restrict the parameters of the private sector equations to be the same for all three countries. Our preferred specification is the constrained version of the FM-model which has a marginal data density that is more than $40 \log$ points higher than the NK alternative. Our findings also demonstrate that cross-country macroeconomic differences are well explained by the different shocks that hit each economy and by differences in the ways in which national central banks reacted to those shocks.
\end{abstract}

\author{
Roger Farmer \\ UCLA \\ Department of Economics \\ Box 951477 \\ Los Angeles, CA 90095-1477 \\ and CEPR \\ and also NBER \\ rfarmer@econ.ucla.edu \\ Giovanni Nicolò \\ Federal Reserve Board \\ 20th St \& Constitution Avenue NW \\ Washington, DC, 20551 \\ giovanni.nicolo@frb.gov
}




\section{Some International Evidence for Keynesian Economics Without the Phillips Curve*}

\author{
By Roger E.A. FARMER ${ }^{\dagger}$
}

\author{
GIOVANNi NiCOLÒ
}

Farmer and Nicolò (2018) show that the Farmer Monetary (FM)model outperforms the three-equation New-Keynesian (NK)-model in post war U.S. data. In this paper, we compare the marginal data density of the FM-model with marginal data densities for determinate and indeterminate versions of the NK-model for three separate samples using U.S., U.K. and Canadian data. We estimate versions of both models that restrict the parameters of the private sector equations to be the same for all three countries. Our preferred specification is the constrained version of the FM-model which has a marginal data density that is more than 40 log points higher than the NK alternative. Our findings also demonstrate that cross-country macroeconomic differences are well explained by the different shocks that hit each economy and by differences in the ways in which national central banks reacted to those shocks.

\section{Introduction}

The Phillips curve (Phillips, 1958) was introduced into macroeconomics in the 1960s as a way of endogenising prices in the IS-LM framework that John Hicks (1937) and Alvin Hansen (1936) had developed to popularize Keynes' General Theory (Keynes, 1936). The Phillips curve, and its modern variant, the NewKeynesian (NK) Phillips curve (Galí, 2008), have fallen out of favour in recent years (Farmer, 2013, 2016) as unemployment has fallen to record low levels with no apparent resurgence of either wage or price inflation.

In a recent paper presented at the 9th Manchester Conference on Growth and Business Cycles in Theory and Practice, Farmer presented empirical evidence (Farmer and Nicolò, 2018) in favour of an alternative to the New-Keynesian model. ${ }^{1}$ This alternative, the Farmer Monetary Model (FM-Model), replaces the NK-Phillips curve with a belief function. The FM-model originated in Farmer

\footnotetext{
* The views expressed in this paper are those of the authors and do not necessarily reflect the views of the Federal Reserve Board or the Federal Reserve System.

$\dagger$ Affiliations: Department of Economics, University of Warwick; National Institute of Economic and Social Research and University of California Los Angeles. Email: r.farmer.1@warwick.ac.edu.

$\ddagger$ Affiliation: Federal Reserve Board. Email: giovanni.nicolo@frb.gov.

${ }^{1}$ We thank George Bratsiotis for inviting us to present this paper at the 9th annual conference organized by the Centre of Growth and Economic Business Cycles at the University of Manchester on July 5 th -6 th 2018 .
} 
(2012) and is further developed in Farmer and Platonov (2019). The belief function is a concept that was introduced in Farmer (1993) as a way of closing models that would otherwise be indeterminate. Farmer (2016) argues that the belief function should be accorded the same methodological status as preferences and technology.

Macroeconomic data among advanced economies show distinct cross-country differences. These differences could potentially be attributed to one of three causes. First: Private sector saving rates or private sector risk aversion parameters may differ. Second: The size and sequence of the shocks that each country experienced might vary (Sims and Zha, 2006; Primiceri, 2005). Finally, institutions, such as the central bank, in each country could operate differently and respond to macroeconomic shocks by adopting distinct monetary policies (Clarida et al., 2000; Lubik and Schorfheide, 2004; Canova and Gambetti, 2009).

In this paper, we ask: Why do the data look different across countries? We focus on three advanced economies: the United States, the United Kingdom and Canada. To explain the observed differences in the macroeconomic behaviour of real GDP, the inflation rate and the yields on 3-month Treasury securities, we compare the FM-model (Farmer, 2012), closed with a belief function, with the New-Keynesian model, closed with the NK-Phillips curve. ${ }^{2}$ In line with the findings of Farmer and Nicolò (2018), we show that the FM-model outperforms the NK-model on U.S., U.K. and Canadian data. Considering all three countries, the FM-model has a marginal data density that exceeds the best performing NK specification by a considerable margin.

To identify the reasons for differences in the data among the United States, the United Kingdom and Canada, we estimated two alternative specifications of the FM-model and the NK-models over the full sample, from 1961Q1 to 2007Q4, and over two sub-samples corresponding to the break in U.S. monetary policy in 1979Q3. For our first specification, we estimated a version of the FM- and NKmodels in which we allowed the private sector, the conduct of monetary policy and the size of the fundamental shocks to differ across countries. For our second specification, we estimated restricted versions of each model in which we constrained the private sector equations to have common parameters across countries.

For both the NK- and the FM-model, we found strong evidence in favour of the constrained specification in which the parameters of the private sector equations were restricted to be the same in all three countries. We conclude that crosscountry macroeconomic differences were caused by differences in the shocks that hit each economy and that the Fed, the Bank of England and the Bank of Canada conducted distinct monetary policies in response to these shocks.

In our previous work, we used a version of the Taylor Rule (Taylor, 1999) to model the central bank reaction function and, as in the paper by Lubik and

\footnotetext{
${ }^{2}$ Farmer (Farmer, 2012) introduced the FM-model to explain persistent high unemployment. Farmer and Platonov (2019) explain the relationship between the FM-model and alternative interpretations of the textbook IS-LM model (Mankiw, 2010) on which modern New-Keynesian models are based.
} 
Schorfheide (2004), we allowed for the Taylor Rule to be either active or passive (Leeper, 1991). We follow that same approach in our current work and in line with our previous findings for the U.S. case (Farmer and Nicolò, 2018), we find that the FM-model is indeterminate in both sub-periods. Moreover, while our preferred specification for the NK-model also found indeterminacy in both sub-periods, the FM-model outperforms the NK-model in the U.S., U.K. and Canadian data in the full sample estimates and in both sub-samples.

\section{Data Used in Our Study}

The data used for our study are plotted in Figures 1, 2 and 3. For each country, we used three time series for the period from 1961Q1 through 2007Q4. ${ }^{3}$ The initial date is constrained by data availability, and the ending date is chosen to coincide with the onset of the Great Recession. ${ }^{4}$

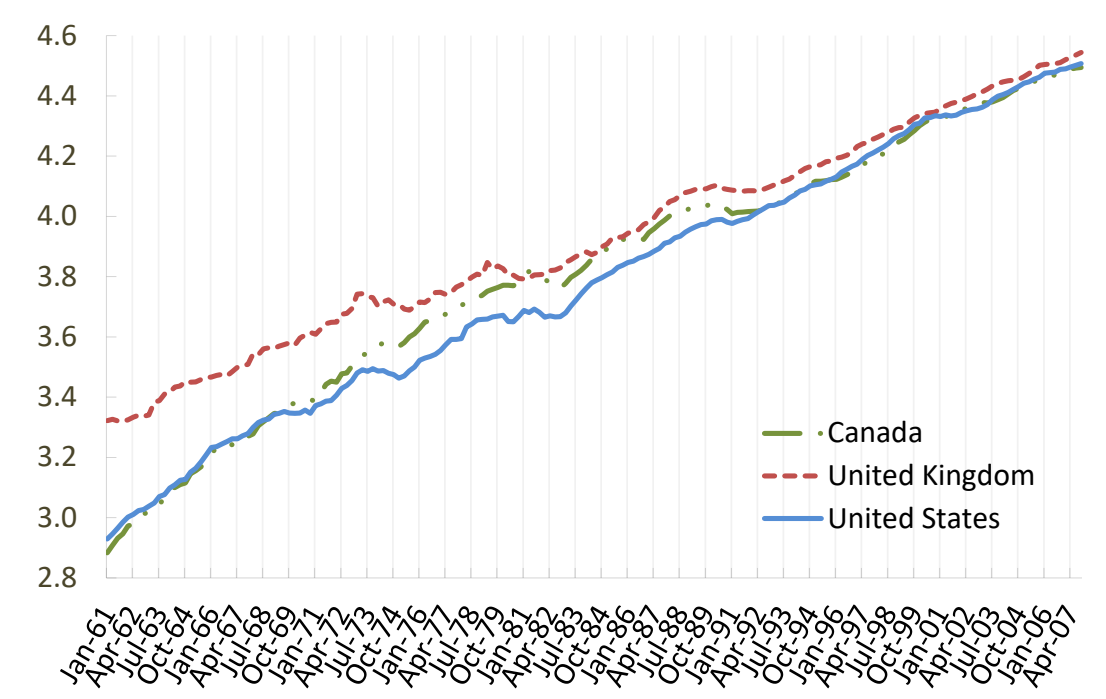

Figure 1. : Total Gross Domestic Product over the period 1961Q1 - 2007Q4 (Index $2015=100$, expressed in logs).

Source: FRED, Federal Reserve Bank of St. Louis.

Figure 1 plots the logarithms of real GDP for the three countries. The solid line reports the data for the U.S., the dashed line represents the U.K. and the dashdotted line describes the Canadian case. Figure 2 reports the CPI inflation rate

\footnotetext{
${ }^{3}$ Appendix A presents further details about the data used for the empirical study. The availability of data for the real GDP for Canada starts in 1961Q1 which dictates the choice of our initial sample date.

${ }^{4}$ We chose to end at that date to avoid potential inaccuracies with our linear approximation to the Taylor Rule that would be expected to arise as a consequence of the constraint that the interest rate must remain non-negative.
} 


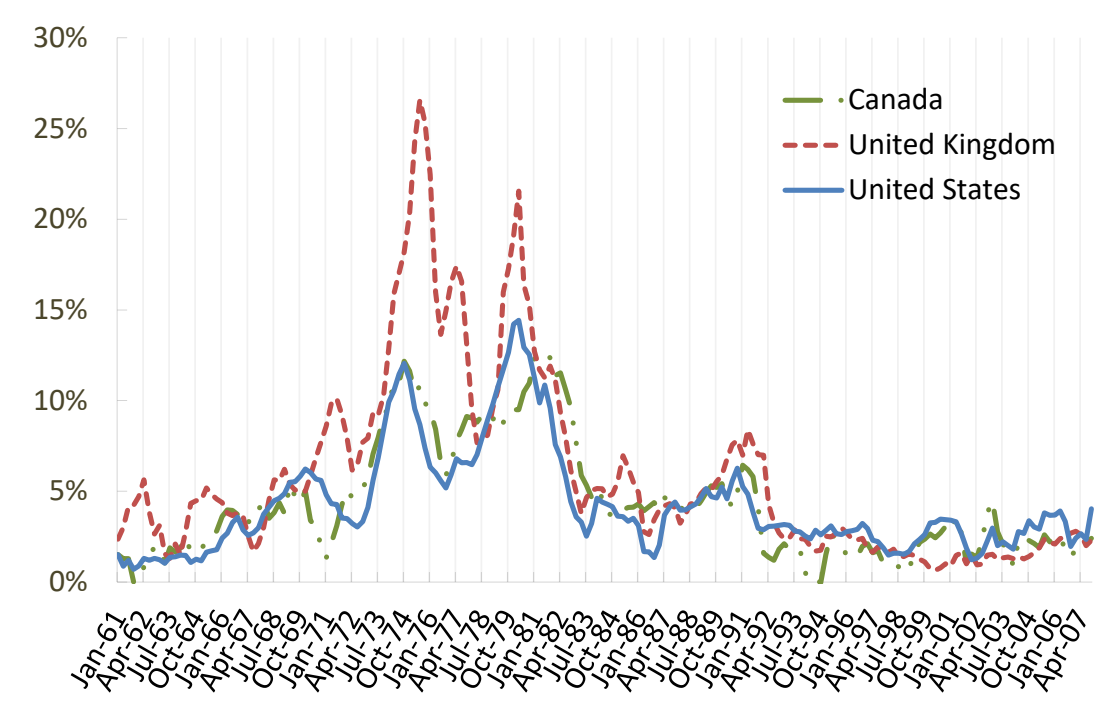

Figure 2. : Inflation rates over the period 1961Q1 - 2007Q4.

Source: FRED, Federal Reserve Bank of St. Louis.

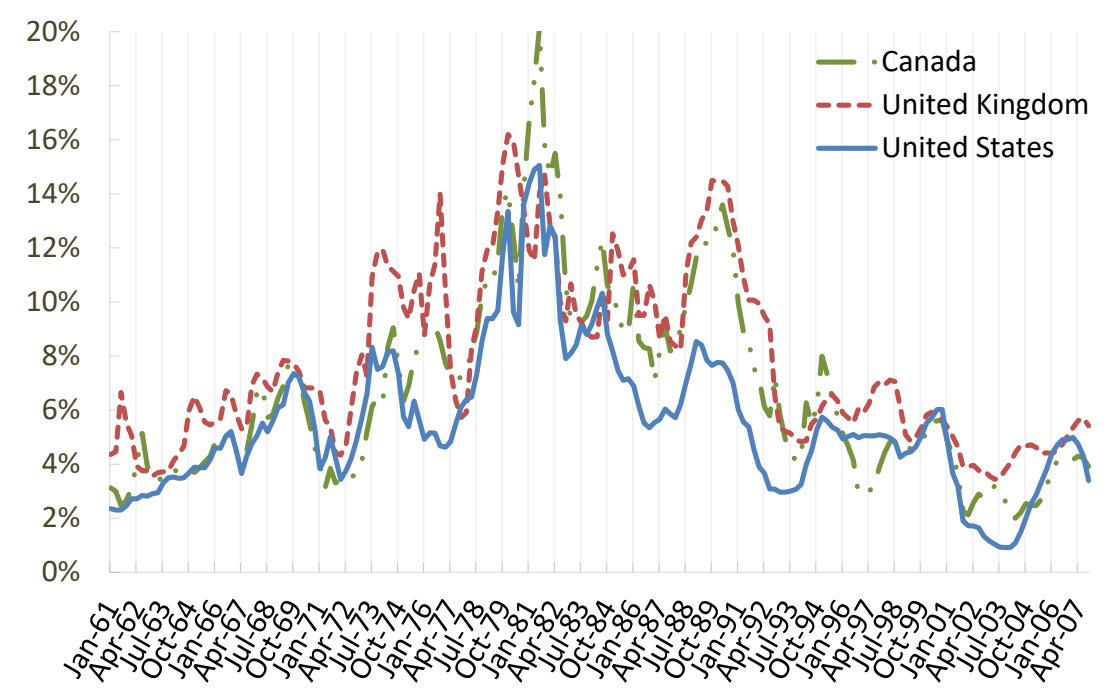

Figure 3. : Nominal interest rates over the period 1961Q1 - 2007Q4.

Source: FRED, Federal Reserve Bank of St. Louis. 
for the three countries and Figure 3 presents the 3-month yields on the Treasury Securities issued by the public sector in each country.

Visual inspection of Figure 2 suggests that there is a break in the behaviour of inflation around 1980. For the case of the United States, this apparent break is confirmed by structural break tests (Beyer and Farmer, 2007) which place the date of the break as 1979Q3. This date coincides with the disinflation initiated when Paul Volcker became Chairman of the Federal Reserve System.

In line with earlier studies (Clarida et al., 2000; Lubik and Schorfheide, 2004; Primiceri, 2005), we estimated the FM- and the NK- models over the full sample as well as over two separate sub-samples. We ran constrained and unconstrained specifications of both models for the full sample and for both sub-samples. Our first sub-sample runs from 1961Q1 through 1979Q2. Our second sub-sample runs from 1982Q4 to 2007Q4. We excluded the quarters from 1979Q3 through 1982Q3 because, over that period, the Fed explicitly targeted the growth rate of the money supply, a policy rule that is inconsistent with our formulation of the central bank reaction function which we model with a Taylor Rule (Taylor, 1999).

\section{The Structural Forms of the FM- and NK-Models}

In our previous work (Farmer and Nicolò, 2018), we explained how the FM- and NK-models differ. The reduced form of the FM-model is a Vector Error Correction Model (VECM) which allows for non-stationary, but co-integrated behaviour of the three observable variables. In contrast, the reduced form of the NK-model is a conventional Vector-autoregression (VAR). For completeness, in section III, we reproduce the argument from Farmer and Nicolò (2018, Section II).

The FM- and the NK-models that we estimate in our empirical work have two equations in common. One of these is a generalization of the NK IS curve that arises from the Euler equation of a representative agent. The other is a policy rule that describes how the Fed sets the fed funds rate. The two common equations of our study are described below.

\section{A. Two Equations that the FM- and NK-Models Share in Common}

We assume the log of potential real GDP grows at a constant rate that we estimate for each country. Unlike our previous work (Farmer and Nicolò, 2018), in our cross country analysis we estimated the trend growth of GDP in one step by allowing the measurement equation in the Kalman filter to contain a trend. We explain that process further in Section IV. The output gap is defined as the difference between the estimated trend and the logarithm of the real GDP series for each country.

The FM-model implies that the output gap is non-stationary and cointegrated with the CPI inflation rate and the federal funds rate. The NK-model implies that the output gap is stationary. In Equations (1) and (2), $y_{t}$ is the difference of the log of GDP from its estimated trend, $R_{t}$ is the federal funds rate and $\pi_{t}$ 
is the CPI inflation rate. The term $z_{d, t}$ is a demand shock, $z_{R, t}$ is a policy shock and $z_{s, t}$ is a supply shock.

$$
\begin{gathered}
a y_{t}-a \mathbb{E}_{t}\left(y_{t+1}\right)+\left[R_{t}-\mathbb{E}_{t}\left(\pi_{t+1}\right)\right] \\
=\eta\left(a y_{t-1}-a y_{t}+\left[R_{t-1}-\pi_{t}\right]\right)+(1-\eta) \rho+z_{d, t} . \\
R_{t}=\rho_{R} R_{t-1}+\left(1-\rho_{R}\right)\left[\bar{r}+\lambda \pi_{t}+\mu\left(y_{t}-z_{s, t}\right)\right]+z_{R, t} .
\end{gathered}
$$

Equation (1) is a generalization of the dynamic IS curve that appears in standard representations of the NK-model. In the special case when $\eta=0$ this equation can be derived from the Euler equation of a representative agent. ${ }^{5}$ The shock $z_{d, t}$ represents a demand shifter of the IS curve and is assumed to follow an autoregressive process of the form $z_{d, t}=\rho_{d} z_{d, t-1}+\varepsilon_{d, t}$. The supply shock $z_{s, t}$ also follows the autoregressive process, $z_{s, t}=\rho_{s} z_{s, t-1}+\varepsilon_{s, t}$.

Equation (2) is a Taylor Rule (Taylor, 1999) that represents the response of the monetary authority to the lagged nominal interest rate, the inflation rate and the output gap. The monetary policy shock, $z_{R, t}$, denotes innovations to the nominal interest rate caused by unpredictable actions of the monetary authority. The parameters $\rho_{R}, \lambda$ and $\mu$ are policy elasticities of the fed funds rate with respect to the lagged fed funds rate, the inflation rate and the output gap.

\section{B. Two Equations that Differentiate the FM- and NK-Models}

The third equation of the NK-model is given by

$$
\pi_{t}=\beta \mathbb{E}_{t}\left[\pi_{t+1}\right]+\phi\left(y_{t}-z_{s, t}\right) .
$$

Here, $\beta$ is the discount rate of the representative person and $\phi$ is a compound parameter that depends on the frequency of price adjustment. ${ }^{6}$ Since $\beta$ is expected to be close to one, we will impose the restriction $\beta=1$ when discussing the theoretical properties of the model. This restriction implies that the long-run Phillips curve is vertical. If instead, $\beta<1$, the NK-model has an upward sloping long-run Phillips curve in inflation-output gap space. An extensive literature derives the NK-Phillips curve from first principles, see for example Galí (2008),

\footnotetext{
${ }^{5}$ See for example Galí (2008), or Woodford (2003). An equation of this form for the general case when $\eta \neq 0$ can be derived from a heterogeneous agent model (Farmer, 2018) where the lagged real interest rate captures the dynamics of borrowing and lending between patient and impatient groups of people. In the case when $\eta=0$, the parameter $a$ is the inverse of the intertemporal elasticity of substitution and $\rho$ is the time preference rate.

${ }^{6}$ In the NK-model, the discount parameter $\beta$ that appears in the Phillips curve is related to the parameter $\rho$ that appears in the IS curve by the identity $\beta \equiv \frac{1}{1+\rho}$. We did not impose that restriction in our estimates. If we had imposed it, our results in favour of the FM-model would have been even stronger since the restriction does not hold exactly in the estimates of the NK-model.
} 
based on the assumption that frictions of one kind or another prevent firms from quickly changing prices in response to changes in demand or supply shocks.

In contrast to the NK-Phillips curve, the third equation of the FM-model is a belief function. Following Farmer $(1993,2012)$, the functional form for the belief function that we use in this study is described by Equation (3.b),

$$
\mathbb{E}_{t}\left[x_{t+1}\right]=\gamma x_{t}+(1-\gamma) \mathbb{E}_{t-1}\left[x_{t}\right]
$$

where $x_{t} \equiv \pi_{t}+\left(y_{t}-y_{t-1}\right)$ is the growth rate of nominal GDP. The belief function is a mapping from current and past observable variables to probability distributions over future economic variables and the functional form that we chose for the belief function, captured by Equation (3.b), asserts that agents' expectations about future nominal GDP growth are adaptive.

When we estimated the model, we found that the data strongly favour the parameter restriction, $\gamma=1$ and in Section $\mathrm{V}$ we report the estimates of the FMmodel under this restriction. When we incorporate this restriction into the belief function, our model implies that beliefs about future nominal income growth are equal to current nominal income growth. By modeling beliefs about future nominal income growth as a new fundamental we resolve both dynamic and static indeterminacy.

In the FM-model, the monetary authority chooses whether changes in the current growth rate of nominal GDP will cause changes in the expected inflation rate or in the output gap. Importantly, these changes will be permanent. The belief function, interacting with the policy rule, selects how demand and supply shocks are distributed between permanent changes to the output gap, and permanent changes to the expected inflation rate.

\section{The Steady-State Properties of the FM- and NK-Models}

In this section, which reproduces our argument in Farmer and Nicolò (2018, Section III), we compare the theoretical properties of the non-stochastic steadystate equilibria of the NK and FM-models. The NK-model has a unique steadystate equilibrium. The FM-model, in contrast, has a continuum of non-stochastic steady-state equilibria. Which of these equilibria the economy converges to depends on the initial condition of a system of dynamic equations. This property is known as hysteresis.

Rather than treat the multiplicity of steady state equilibria as a deficiency, as is often the case in economics, we follow Farmer (1993) by defining a new fundamental, the belief function. When the model is closed in this way, equilibrium uniqueness is restored and every sequence of shocks is associated with a unique sequence of values for the three endogenous variables.

We begin by shutting down shocks and describing the theoretical properties of the steady-state of the NK-model. The values of the steady-state inflation rate, interest rate and output gap in the NK-model are given by the following equations 


$$
\bar{\pi}=\frac{\phi(\bar{r}-\rho)}{\phi(1-\lambda)-\mu(1-\beta)}, \quad \bar{R}=\rho+\bar{\pi}, \quad \bar{y}=\bar{\pi} \frac{(1-\beta)}{\phi} .
$$

When $\beta<1$, the long-run Phillips curve, in output gap-inflation space, is upward sloping. As $\beta$ approaches 1, the slope of the long-run Phillips curve becomes vertical and these equations simplify as follows,

$$
\bar{\pi}=\frac{(\bar{r}-\rho)}{(1-\lambda)}, \quad \bar{R}=\rho+\bar{\pi}, \quad \bar{y}=0 .
$$

For this important special case, the steady state of the NK-model is defined by Equations (4).

Contrast this with the steady state of FM-model, which has only two steady state equations to solve for three steady state variables. These are given by the steady state version of the generalized dynamic IS curve, Equation (1), and the steady state version of the Taylor Rule, Equation (2).

The FM-model is closed with the belief function. In this paper, the specific implementation of the belief function assumes that agents form adaptive expectations about future nominal income growth. This equation does not provide any additional information about the non-stochastic steady state of the model because the same variable, steady-state nominal income growth, appears on both sides of the equation.

Solving the steady-state versions of equations (1) and (2) for $\bar{\pi}$ and $\bar{R}$ as a function of $\bar{y}$ delivers two equations to determine the three variables, $\bar{\pi}, \bar{R}$ and $\bar{y}$.

$$
\bar{\pi}=\frac{(\bar{r}-\rho)}{(1-\lambda)}+\frac{\mu}{(1-\lambda)} \bar{y}, \quad \bar{R}=\rho+\bar{\pi} .
$$

The steady-state of the FM-model is under-determined because there are only two equations to determine three variables. We refer to this property as static indeterminacy. Static indeterminacy is a source of endogenous persistence that enables the FM-model to match the high persistence of the unemployment rate in data.

In standard economic models, the approximate system that describes how the variables evolve through time is a linear difference equation with a point attractor. In the absence of stochastic shocks, the model economy converges asymptotically to this point. In the FM-model the approximate system that describes how the variables evolve through time is a linear difference equation with a one dimensional line as its attractor. In the absence of stochastic shocks, the model economy converges asymptotically to a point on this line; but which point it converges to depends on the initial condition. The reduced form representation of the FMmodel is a VECM, as opposed to a VAR.

An implication of the static indeterminacy of the FM-model is that policies 
that affect aggregate demand have permanent long-run effects on the output gap and the unemployment rate. In contrast, the NK-model incorporates the Natural Rate Hypothesis, a feature which implies that demand management policy cannot affect real economic activity in the long-run.

\section{The Dynamic Properties of the FM- and NK-Models}

In this section, which is reproduced from (Farmer and Nicolò, 2018, Section IV), we discuss the dynamic properties of the FM-model and compare them with the NK-model. For both models we study the special case of $\rho_{R}=0$, and $\eta=0$. The first of these restrictions sets the response of the Fed to the lagged interest rate to zero. The second restricts the IS curve to the representative agent case. These restrictions allow us to generate, and compare, analytical expressions for the Taylor Principle in both models.

The special cases of Equations (1) and (2) are given by

$$
a y_{t}=a E_{t}\left(y_{t+1}\right)-\left(R_{t}-\mathbb{E}_{t}\left(\pi_{t+1}\right)\right)+\rho+z_{d, t},
$$

and

$$
R_{t}=\bar{r}+\lambda \pi_{t}+\mu\left(y_{t}-z_{s, t}\right)+z_{R, t} .
$$

In the NK-model, the Taylor Principle directs the central bank to increase the federal funds rate by more than one-for-one in response to an increase in the inflation rate. When the Taylor Principle is satisfied, the dynamic equilibrium of the NK-model is locally unique. When that property holds, we say that the unique steady state is locally determinate (Clarida et al., 1999).

When the central bank responds only to the inflation rate, the Taylor principle is sufficient to guarantee local determinacy. When the central bank responds to the output gap as well as to the inflation rate, a sufficient condition for the NK-model to be locally determinate is that

$$
\left|\lambda+\frac{1-\beta}{\phi} \mu\right|>1
$$

For the FM-model, we refer to the analysis in Farmer and Nicolò (2018) which shows that for the special case of logarithmic preferences, corresponding to the parameter restriction $a=1$, a sufficient condition for local determinacy in the FM-model is,

$$
\left|\frac{\lambda}{\lambda-\mu}\right|>1
$$

This is the FM analog of the Taylor principle for this special case. When this condition holds, each element of the set of steady state equilibria of the model is 
dynamically determinate.

The form of the determinacy condition has no simple closed form for general values of the parameters. We were, however, able to derive an analytic expression for the case when $\lambda=\mu$. Here, the Taylor Principle requires the following inequality to hold, ${ }^{7}$

$$
a<1+\frac{\lambda}{2}
$$

Given our estimates of $a, \lambda$ and $\mu$ in our previous study, we found that the determinacy condition is violated in the U.S. data. Our current paper finds the same result when we extend our analysis to include U.K. and Canadian data.

The conjunction of static and dynamic indeterminacy provides two sources of endogenous persistence. Static indeterminacy implies that the output gap contains an I(1) component. Instead of converging to a point in interest-rateinflation-output gap space, the data converge to a one-dimensional linear manifold. Dynamic indeterminacy implies that the fed funds rate, the inflation rate and the unemployment rate display persistent deviations from this manifold.

Dynamic indeterminacy allows the FM-model to explain why prices appear to move slowly in data. In a model with fully flexible prices and a locally unique equilibrium, current and expected future prices respond on impact to a monetary shock to maintain a constant real interest rate. In the FM-model, where equilibria are locally dynamically indeterminate, agents form self-fulfilling expectations that generate a source of endogenous persistence in response to a monetary shock. ${ }^{8}$

In contrast to the NK-model, prices are not sticky in the sense that there is a cost or barrier to price adjustment. They are sticky because people believe, correctly, that future prices will validate their decision to demand fewer goods and services in response to an increase in the money interest rate. ${ }^{9}$

\section{Estimating the FM- and NK-Models on U.S., U.K. and Canadian Data}

To estimate the parameters of the FM- and NK-models we used data on CPI inflation rates and nominal interest rates and data on real GDP in levels. To relate the theoretical model, which contains the output gap as a variable, we specified a measurement equation that maps data on real GDP and a time trend

\footnotetext{
${ }^{7}$ In Farmer and Nicolò (2018) this inequality is mistakenly cited as a condition for indeterminacy.

8 We thank Martin Ellison (2018) for his discussion of our previous work (Farmer and Nicolò, 2018). Ellison (2018) highlighted the role that the covariance terms between the sunspot shock, $\eta_{2}$, and the exogenous shocks play in determining the dynamics of inflation. In our previous work, we assumed that the sunspot shock was uncorrelated with fundamental disturbances, implying that prices were predetermined and could only respond with a lag to exogenous shocks. In contrast, the version of the FMmodel in Section IV allows us to estimate the covariance terms. This approach ensures that exogenous disturbances could have a contemporaneous impact on inflation when the estimated covariance differs from zero.

${ }^{9}$ The idea that indeterminacy can explain sticky prices was discussed in Farmer (1991) and developed further in Farmer (1992) and Farmer (2000). See also Matheny (1998) and Benhabib and Farmer (2000).
} 
into the theoretical concept, $y_{t}$.

$$
y_{t}^{o b s}=\left(c_{y}+g_{y} t\right)+y_{t} .
$$

Here, $c_{y}$ and $g_{y}$ represent the intercept and the slope of a linear trend that characterizes the data on real GDP (expressed in logs). Equation (9) implies that the log of real GDP grows at a constant rate, and it defines the output gap as the residual of a regression of the log of real GDP on a constant and a time trend.

\begin{tabular}{cccc}
\hline \multicolumn{4}{c}{ Table 1: Calibration of intercept parameter $c_{y}$} \\
\hline \hline & United States & United Kingdom & Canada \\
\hline$c_{y}$ & 3.03 & 3.33 & 3.08 \\
\hline \hline
\end{tabular}

Because the FM-model is characterized by static indeterminacy, the intercept terms in the growth regressions are not identified. To handle this problem, we calibrated the intercept terms using country-specific least-squares regressions, while allowing the slope coefficients to be separately identified as part of the full model estimation step. ${ }^{10}$ Table 1 records the values we obtained for this calibration and Appendix B reports the calibrated values for $c_{y}$ when the models were estimated over separate sub-samples.

The FM- and NK-models are examples of structural Dynamic Stochastic General Equilibrium models and they each contain forward looking expectations in the model equations. To estimate a model in this class, the model must first be solved by computing its reduced form. To compute the reduced forms of the FMand NK-models, we applied the method developed in Bianchi and Nicolò (2017) which can handle structural models that may have an arbitrary degree of indeterminacy. We estimated the parameters of the constrained and unconstrained specifications of both models for the full sample and for the two sub-samples using a Markov-Chain Monte-Carlo algorithm, implemented in DYNARE (Adjemian et al., 2011). Table 2 summarizes the prior distributions that we adopted. The table reports the prior shape, mean, standard deviation and $90 \%$ probability interval.

We centered the prior for the slope parameter of the linear trend in the (logarithm of) real GDP, $g_{y}$, to 0.007 , implying a $2.8 \%$ annualized growth rate and we set the standard deviation of the supply shock, $\sigma_{s}$, to 0.1 . We made this choice because earlier studies found that the variance of supply shocks was higher in the pre-Volcker sample as a consequence of two major oil-price shocks in the 1970s (Primiceri, 2005; Sims and Zha, 2006).

\footnotetext{
${ }^{10}$ Calibrating $c_{y}$ in this way corresponds to choosing a reference path for the output gap. By calibrating this parameter, we substantially improved the convergence of the model parameters during our estimation.
} 
Our priors for $a, \lambda$ and $\mu$ place the FM-model in the indeterminacy region of the parameter space. This is consistent with our exploratory estimates for the U.S. data in which we compared posterior odds ratios for determinate and indeterminate regions of the parameter space for the FM-model. We found that the likelihood that the model parameters lie in the determinacy region for the FM-model is zero.

For the case of the NK-model, Lubik and Schorfheide (2004) found that the U.S. data favour the indeterminacy region for the pre-Volcker sample and the determinacy region for the post-Volcker sample. For this reason, we estimated constrained and unconstrained versions of the NK-model for both regions of the parameter space and we report all six sets of results.

\begin{tabular}{lccccc}
\hline \multicolumn{7}{l}{ Table 2: Prior distributions } & & & \\
\hline \hline Name & Range & Density & Mean & Std. Dev. & $90 \%$ interval \\
\hline$a$ & $\mathbb{R}^{+}$ & Gamma & 3.5 & 0.50 & {$[2.67,4.32]$} \\
$\rho$ & $\mathbb{R}^{+}$ & Gamma & 0.02 & 0.005 & {$[0.012,0.029]$} \\
$\eta$ & {$[0,1]$} & Beta & 0.9 & 0.05 & {$[0.81,0.97]$} \\
\hline $\bar{r}$ & {$[0,0.1]$} & Uniform $[0,0.1]$ & 0.05 & 0.029 & {$[0.005,0.095]$} \\
$\rho_{R}$ & {$[0,1]$} & Beta & 0.85 & 0.10 & {$[0.65,0.97]$} \\
$\lambda$ & $\mathbb{R}^{+}$ & Gamma & 1.5 & 0.50 & {$[0.78,2.40]$} \\
$\mu$ & $\mathbb{R}^{+}$ & Gamma & 0.70 & 0.20 & {$[0.41,1.06]$} \\
\hline$g_{y}$ & $\mathbb{R}$ & Normal & 0.007 & 0.002 & {$[0.004,0.010]$} \\
$\rho_{d}$ & {$[0,1]$} & Beta & 0.90 & 0.05 & {$[0.81,0.97]$} \\
$\rho_{s}$ & {$[0,1]$} & Beta & 0.90 & 0.05 & {$[0.81,0.97]$} \\
\hline$\sigma_{R}$ & $\mathbb{R}^{+}$ & Inverse Gamma & 0.01 & 0.003 & {$[0.006,0.015]$} \\
$\sigma_{d}$ & $\mathbb{R}^{+}$ & Inverse Gamma & 0.01 & 0.003 & {$[0.006,0.015]$} \\
$\sigma_{s}$ & $\mathbb{R}^{+}$ & Inverse Gamma & 0.1 & 0.03 & {$[0.06,0.15]$} \\
\hline$\sigma_{\eta_{2}}$ & $\mathbb{R}^{+}$ & Inverse Gamma & 0.005 & 0.003 & {$[0.002,0.010]$} \\
$\rho_{R, \eta_{2}}$ & {$[-1,1]$} & Uniform $[-1,1]$ & 0 & 0.57 & {$[-0.9,0.9]$} \\
$\rho_{d, \eta_{2}}$ & {$[-1,1]$} & Uniform $[-1,1]$ & 0 & 0.57 & {$[-0.9,0.9]$} \\
$\rho_{s, \eta_{2}}$ & {$[-1,1]$} & Uniform $[-1,1]$ & 0 & 0.57 & {$[-0.9,0.9]$} \\
\hline \hline$\beta$ & {$[0,1]$} & Beta & 0.97 & 0.01 & {$[0.95,0.98]$} \\
$\phi$ & $\mathbb{R}^{+}$ & Gamma & 0.50 & 0.20 & {$[0.22,0.87]$} \\
\hline \hline
\end{tabular}

For the case of an indeterminate equilibrium, the Bianchi and Nicolò (2017) method requires the researcher to reclassify one of the endogenous forecast errors of the model as a new fundamental. In our estimates we selected a unique equilibrium by choosing the forecast error

$$
\eta_{2, t} \equiv \pi_{t}-\mathbb{E}_{t-1}\left[\pi_{t}\right]
$$

to play the role of a new fundamental. We denote the standard deviation of 
this new fundamental shock by $\sigma_{\eta_{2}}$ and we specify new parameters to represent the covariance of $\eta_{2, t}$ with the other fundamental shocks in the model. These parameters are represented by the symbols $\rho_{x, \eta_{2}}$ where $x=\{R, d, s\} .{ }^{11}$ When these covariance terms are non-zero, all of the shocks may have a contemporaneous impact on inflation by affecting the expectations that agents have about expected future prices. ${ }^{12}$

\section{A Discussion of our Results}

In this section, we ask if the cross-country data can be explained by a model in which the private sector equations are restricted to be the same across countries and we compare posterior marginal data densities for three different sample periods and for eighteen alternative models.

For the full sample, and for each sub-sample, we estimated constrained and unconstrained versions of the FM-model. We compared our parameter estimates with those obtained by estimating constrained and unconstrained versions of the NK-model in both the determinate and indeterminate regions of the parameter space. In all cases, the constrained FM-model outperformed all alternative specifications of the NK-model by a considerable margin.

For the FM-model, the parameters of the private sector equations consist of the degree of risk aversion, the discount parameter, and the persistence parameter $\eta$. For the NK-model the parameter set also includes the parameters of the NKPhillips curve. For the constrained specifications of each model, we restricted all of the private sector parameters to be the same across countries.

In Model 1, Fully unrestricted, we estimated all the parameters of the FM-model separately for each country. In Model 2, Constrained, we allowed the parameters of the policy rule and the shock processes to vary across countries, while we constrained the parameters associated with the private sector to be common. We found that for both models, we could not reject the restrictions that the private sector parameters are the same across all three countries. We report these findings in Table 3.A.

The logarithms of the marginal data densities were computed using Geweke's (1999) modified Harmonic mean estimator. Unlike a standard likelihood ratio statistic, the marginal data density penalizes a model that is over-parameterized. It is possible, as we find in this instance, that a restricted model can have a higher posterior probability than an unrestricted model. In three of the model comparisons that we report in Table 3.A, the constrained model outperforms the unconstrained model by more than 5 log points.

\footnotetext{
${ }^{11}$ For the methodology behind our estimation procedure the reader is referred to Farmer et al. (2015) and Bianchi and Nicolò (2017). These papers establish that, as long as the covariance terms are unrestricted, choosing $\eta_{2}$ as a new fundamental is equivalent to the choice of $\eta_{1, t} \equiv y_{t}-\mathbb{E}_{t-1}\left[y_{t}\right]$. There is a one-to-one transformation that maps one representation of the model into the other.

${ }^{12}$ We direct the readers to footnote 8 and Ellison (2018) for a more in-depth discussion of the role of the covariance terms in determining the dynamics of the inflation rate.
} 


\begin{tabular}{|c|c|c|c|}
\hline & & Fully unrestricted & Constrained \\
\hline Full sample & Log data density & 5448.0 & 5466.5 \\
\hline Pre-Volcker & Log data density & 2082.7 & 2087.8 \\
\hline Post-Volcker & Log data density & 3171.0 & 3205.9 \\
\hline
\end{tabular}

\begin{tabular}{|c|c|c|c|}
\hline & & Fully unrestricted & Constrained \\
\hline Full sample & Log data density & 5420.3 & 5403.7 \\
\hline Pre-Volcker & Log data density & 2074.7 & 2079.4 \\
\hline Post-Volcker & Log data density & 2905.6 & 3064.5 \\
\hline
\end{tabular}

\begin{tabular}{lccc}
\hline \multicolumn{3}{c}{ Table 3.C: Model specifications } & NK-model - determinacy \\
\hline & & Fully unrestricted & Constrained \\
\hline Full sample & Log data density & 4788.5 & 5034.2 \\
Pre-Volcker & Log data density & 1916.0 & 2000.9 \\
Post-Volcker & Log data density & 2828.4 & 2860.4 \\
\hline
\end{tabular}

Tables 3.B and 3.C report log data densities from the estimation of the NKmodel under indeterminacy and determinacy, respectively. For both tables, we report the results for the constrained and unconstrained specifications for the full sample and for both sub-samples. We see from comparing the columns of Table 3.B and Table 3.C that in five of six possible comparisons, the log data density of the constrained NK-model, reported in the right-column, is larger than the log data density for the unconstrained NK-model, reported in the left column. The one exception was the indeterminacy specification for the full sample in which the unconstrained model fared better than its constrained counterpart.

Our most important finding comes from comparing the values of the log data density in Table 3.A, which represents the FM-model, with the corresponding entries in Tables $3 \mathrm{~B}$ and $3 \mathrm{C}$, which represent the NK-model for specifications that 
restrict the parameters to be in the indeterminacy region, Table 3.B, or the determinacy region, Table 3.C. Here we see that for all the sample periods considered, each specification of the FM model is preferred to the corresponding version of the NK model. Moreover, when we can compare the largest entries for the FM model with the largest entries for the determinate and indeterminate versions of the NK model, the FM model has a marginal data density that outperforms the best NK alternative by $46 \log$ points for the full sample, 8 log points for the pre-Volcker sample and $140 \log$ points for the post-Volcker sample. These results are in line with the findings in Farmer and Nicolò (2018) for the U.S. case.

We next turn to detailed parameter estimates for the full sample FM-model which we report in Table 4A. Sub-sample parameter estimates for this model are contained in Appendix B.

\begin{tabular}{ccc}
\hline \multicolumn{3}{c}{ Table } \\
\hline \hline & Mean & Posterior estimates, Common parameters \\
\hline$a$ & 5.80 & $90 \%$ prob. int. \\
$\rho$ & 0.026 & {$[5.22,6.55]$} \\
$\eta$ & 0.92 & {$[0.020,0.032]$} \\
\hline \hline
\end{tabular}

Our estimates of the relative risk aversion parameter, $a=5.8$ and the time preference parameter, $\rho=0.026$ are in line with previous studies of these parameters in U.S. data. Our estimate of the parameter $\eta=0.92$ is significantly different from 0 which indicates that the data strongly prefer our generalized version of the IS curve over the conventional representative agent version in which it is equal to 0 . The fact that we find a non-zero value for this parameter is not particularly surprising and is consistent with previous estimates of the NK-model in which researchers often include richer dynamics in the IS curve by allowing for habit formation preferences.

In Table $4 . \mathrm{B}$ we report the posterior mean and $90 \%$ probability interval for the country-specific model parameters for the FM-model. The first block of this table represents our cross-country estimates of the parameters of the Taylor Rule. The parameter $\bar{r}$ is the constant in the Taylor Rule, $\rho_{R}$ is the coefficient on the lagged interest rate, and $\lambda$ and $\mu$ represent the inflation rate and output gap response coefficients. Although these parameters display qualitative similarities, they are statistically different across countries. For example, the posterior mean of the Canadian central bank interest rate response coefficient, $\rho_{R}$, is equal to 0.62 which is outside of the $90 \%$ confidence bounds for the same coefficient in the United States or the United Kingdom.

The Taylor Rule coefficients on inflation are all above 1 which would indicate that the equilibrium in each country are determinate if we were estimating the NK-model. But this is not the relevant test for indeterminacy. Instead, the determinacy condition for the FM model is a complicated function that involves 
not only the parameters of the Taylor Rule, but also the parameters of the IS curve. The relevant condition is that the risk aversion parameter $a$, must be small relative to $\lambda$ and $\mu$. For our estimated values of $a=5.8, \lambda$ less than 1.6 and $\mu$ between 0.25 and 0.6 , we found that the FM version of the Taylor Principle is violated for all three countries.

\begin{tabular}{lcc|cc|cc}
\hline \multicolumn{7}{c}{ Table 4.B: Posterior estimates, Country-specific } \\
\hline \hline \multicolumn{2}{c}{ United States } & \multicolumn{2}{c}{ United Kingdom } & \multicolumn{2}{c}{ Canada } \\
\hline $\bar{r}$ & 0.012 & {$[0.001,0.029]$} & 0.024 & {$[0.001,0.044]$} & 0.008 & {$[0.001,0.018]$} \\
$\rho_{R}$ & 0.86 & {$[0.74,0.93]$} & 0.88 & {$[0.80,0.96]$} & 0.62 & {$[0.56,0.70]$} \\
$\lambda$ & 1.53 & {$[1.09,1.98]$} & 1.29 & {$[0.97,1.63]$} & 1.28 & {$[1.03,1.56]$} \\
$\mu$ & 0.40 & {$[0.20,0.53]$} & 0.51 & {$[0.31,0.72]$} & 0.26 & {$[0.19,0.33]$} \\
\hline$g_{y}$ & 0.008 & {$[0.007,0.008]$} & 0.006 & {$[0.006,0.007]$} & 0.008 & {$[0.007,0.008]$} \\
$\rho_{d}$ & 0.71 & {$[0.65,0.77]$} & 0.70 & {$[0.63,0.79]$} & 0.80 & {$[0.75,0.85]$} \\
$\rho_{s}$ & 0.95 & {$[0.90,0.99]$} & 0.93 & {$[0.87,0.98]$} & 0.94 & {$[0.91,0.98]$} \\
\hline$\sigma_{R}$ & 0.007 & {$[0.006,0.008]$} & 0.008 & {$[0.007,0.009]$} & 0.007 & {$[0.006,0.007]$} \\
$\sigma_{d}$ & 0.017 & {$[0.014,0.020]$} & 0.021 & {$[0.015,0.025]$} & 0.013 & {$[0.010,0.016]$} \\
$\sigma_{s}$ & 0.056 & {$[0.043,0.068]$} & 0.063 & {$[0.046,0.081]$} & 0.053 & {$[0.043,0.064]$} \\
$\sigma_{\eta_{2}}$ & 0.006 & {$[0.005,0.007]$} & 0.013 & {$[0.012,0.014]$} & 0.008 & {$[0.007,0.008]$} \\
\hline$\rho_{R, \eta_{2}}$ & -0.10 & {$[-0.28,0.07]$} & 0.17 & {$[0.01,0.31]$} & -0.03 & {$[-0.19,0.14]$} \\
$\rho_{s, \eta_{2}}$ & 0.72 & {$[0.50,0.98]$} & 0.79 & {$[0.61,0.96]$} & 0.63 & {$[0.48,0.80]$} \\
$\rho_{d, \eta_{2}}$ & 0.20 & {$[0.03,0.37]$} & -0.09 & {$[-0.21,0.04]$} & 0.12 & {$[0.01,0.23]$} \\
\hline \hline
\end{tabular}

The second block of rows of Table $4 \mathrm{~B}$ reports estimates of the growth rates and the auto-correlation parameters $\rho_{d}$ and $\rho_{s}$. The U.K. quarterly growth rate is estimated to be $0.6 \%$ which is lower than the quarterly growth rates for the U.S. and Canada, both of which are estimated at $0.8 \%$. The auto-correlation parameters are qualitatively similar across countries, but estimated precisely enough in each case to reject the hypothesis that these parameters are the same across countries.

Next, we turn our attention to the shock variances and co-variances which are reported in the third and fourth row-blocks of Table 4.B. For all countries, the standard deviation of the innovation to the supply shock, $\sigma_{s}$ is roughly three times larger than the standard deviation of the innovation to the IS shock and eight times larger than the standard deviation of the innovation to either the policy shock or the standard deviation of the innovation to the inflation process, $\sigma_{\eta_{2}}$.

\section{Conclusions}

This paper has two major findings. First, we established that the FM-model outperforms the NK-model in explaining the data for U.S., the U.K. and Canada. 
Second, we found that all of the cross country differences in economic performance for these countries can be attributed to differences in shocks and to the way that their respective central banks responded to these shocks. The equations that describe private sector behaviour appear to be similar, and the specification in which they are constrained to be the same outperforms the unconstrained model by a wide margin. This finding holds for both the FM-model and for five of our six specifications of the NK-model.

It is instructive to ask why the FM-model outperforms the NK alternative. We believe it is because the FM-model displays not only dynamic indeterminacy, but also static indeterminacy. The former property, dynamic indeterminacy, allows the model to explain apparent price-stickiness in the data. The second property, static indeterminacy, allows the FM-model to mimic the co-integrating properties of the interest rate, the inflation rate and the output gap, each of which are well described by non-stationary but cointegrated processes.

The different properties of the FM-model have important policy implications that are explored in Farmer (2016) and Farmer and Platonov (2019). Farmer and Platonov show that, in the FM-model, demand and supply shocks may have permanent effects on employment and inflation. Importantly, beliefs about nominal income growth are fundamentals of the economy that act as an equilibrium selection device. Beliefs influence the output-gap not only during periods of adjustment, but also in the long-run.

In Farmer and Nicolò (2018) we ended our paper with the following paragraph:

Central bankers use the concept of a time-varying natural rate of unemployment before deciding when and if to raise the nominal interest rate. The difficulty of estimating the natural rate arises, in practice, because the economy displays no tendency to return to its natural rate. That fact has led to much recent skepticism about the usefulness of the Phillips curve in policy analysis. Although we are sympathetic to the Keynesian idea that aggregate demand determines employment, we have shown in this paper that it is possible to construct a 'Keynesian economics' without the Phillips curve.

In this companion piece, we have provided additional empirical evidence in favour of the FM-model by demonstrating that our results hold, not only in United States data, but also when we include data from the United Kingdom and Canada.

\section{REFERENCES}

Stéphane Adjemian, Houtan Bastani, Michel Juillard, Junior Maih, Fréderic Karamé, Ferhat Mihoubi, George Perendia, Johannes Pfeifer, Marco Ratto, and Sébastien Villemot. Dynare: Reference manual version 4. Dynare Working Papers, CEPREMAP, 1, 2011. 
Jess Benhabib and Roger E. A. Farmer. The monetary transmission mechanism. Review of Economic Dynamics, 3(3):523-550, 2000.

Andreas Beyer and Roger E. A. Farmer. Natural rate doubts. Journal of Economic Dynamics and Control, 31(121):797-825, 2007.

Francesco Bianchi and Giovanni Nicolò. A Generalized Approach to Indeterminacy in Linear Rational Expectations Models. NBER Working Paper No. 23521, 2017.

Fabio Canova and Luca Gambetti. Structural Changes in the US Economy: Is There a Role for Monetary Policy? Journal of Economic Dynamics and Control, 33:477-490, 2009.

Richard Clarida, Jordi Galí, and Mark Gertler. The science of monetary policy: A new keynesian perspective. Journal of Economic Literature, 37(December): 1661-1707, 1999.

Richard Clarida, Jordi Galí, and Mark Gertler. Monetary policy rules and macroeconomic stability: Evidence and some theory. Quarterly Journal of Economics, 115(1):147-180, 2000.

Martin Ellison. Comments on Keynesian Economics Without the Phillips Curve. Journal of Economic Dynamics and Control, 89:151-153, 2018.

Roger E. A. Farmer. Sticky prices. Economic Journal,, 101(409):1369-1379, 1991.

Roger E. A. Farmer. Nominal price stickiness as a rational expectations equilibrium. Journal of Economic Dynamics and Control, 16(1):317-337, 1992.

Roger E. A. Farmer. The Macroeconomics of Self-Fulfilling Prophecies. MIT Press, Cambridge, MA, first edition, 1993.

Roger E. A. Farmer. Two New Keynesian theories of sticky prices. Macroeconomic Dynamics, 4(1):74-107, 2000.

Roger E. A. Farmer. Animal Spirits, Persistent Unemployment and the Belief Function. In Roman Frydman and Edmund S. Phelps, editors, Rethinking Expectations: The Way Forward for Macroeconomics, chapter 5, pages 251276. Princeton University Press, Princeton, NJ, 2012.

Roger E. A. Farmer. The natural rate hypothesis: An idea past its sell by date. Bank of England Quarterly Bulletin, Q3:244-256, 2013.

Roger E. A. Farmer. Prosperity for All: How to Prevent Financial Crises. Oxford University Press, New York, September 2016.

Roger E. A. Farmer. Pricing Assets in a Perpetual Youth Model. Review of Economic Dynamics, 30:106-124, 2018. 
Roger E. A. Farmer and Giovanni Nicolò. Keynesian Economics Without the Phillips Curve. Journal of Economic Dynamics and Control, 89:137-50, April 2018.

Roger E. A. Farmer and Konstantin Platonov. Animal spirits in a monetary model. European Economic Review, 115:60-77, 2019.

Roger E.A. Farmer, Vadim Khramov, and Giovanni Nicolò. Solving and Estimating Indeterminate DSGE Models. Journal of Economic Dynamics and Control, 54:17-36, 2015.

Jordi Galí. Monetary Policy, Inflation, and the Business Cycle: An Introduction to the New Keynesian Framework. Princeton University Press, 2008.

John Geweke. Using simulation methods for bayesian econometric models: Inference, development, and communication. Econometric Reviews, 18:1-73, 1999.

Alvin Hansen. Mr. Keynes on underemployment equilibrium. Journal of Political Economy, 44(5):667-686, 1936.

John R. Hicks. Mr. Keynes and the classics: A suggested interpretation. Econometrica, 5(2):147-159, April 1937.

John Maynard Keynes. The General Theory of Employment, Interest and Money. MacMillan and Co., London and Basingstoke, 1936. 1973 edition published for the Royal Economic Society, Cambridge.

Eric M. Leeper. Equilibria under 'active' and 'passive' monetary and fiscal policies. Journal of Monetary Economics, 27(1):129-147, 1991.

Thomas A. Lubik and Frank Schorfheide. Testing for indeterminacy: An application to U.S. monetary policy. American Economic Review, 94:190-219, 2004 .

N. Gregory Mankiw. Macroeconomics. Worth, New York, 2010. Seventh Edition.

Kenneth Matheny. Non-neutral responses to money supply shocks when consumption and leisure are pareto substitutes. Economic Theory, 11:379-402, 1998.

Alban W. Phillips. The relationship between unemployment and the rate of change of money wages in the united kingdom 1861-1957. Economica, 25(100): 283-299, 1958.

Giorgio E. Primiceri. Time varying structural vector autoregressions and monetary policy. The Review of Economic Studies, 72:821-852, 2005.

Christopher A. Sims and Tao Zha. Were there regime switches in us monetary policy? American Economic Review, 96(1):54-81, 2006. 
John B. Taylor. An historical analysis of monetary policy rules. In John B. Taylor, editor, Monetary Policy Rules, pages 319-341. University of Chicago Press, Chicago, 1999.

Michael Woodford. Interest and Prices: Foundations of a Theory of Monetary Policy. Princeton University Press, Princeton, N.J., 2003.

\section{Appendix A: Data Sources}

Data for the United States:

- Source: St. Louis FRED Database

- Gross Domestic Product by Expenditure in Constant Prices: Total Gross Domestic Product for the United States, Index 2015=100, Quarterly, Seasonally Adjusted (Series: NAEXKP01USQ661S)

- Consumer Price Index for All Urban Consumers: All Items, Percent Change from Year Ago, Quarterly, Seasonally Adjusted (Series: CPIAUCSL_PC1)

- 3-Month Treasury Bill: Secondary Market Rate, Percent, Quarterly, Not Seasonally Adjusted (Series: TB3MS)

Data for the United Kingdom:

- Source: St. Louis FRED Database

- Gross Domestic Product by Expenditure in Constant Prices: Total Gross Domestic Product for the United Kingdom, Index 2015=100, Quarterly, Seasonally Adjusted (Series: NAEXKP01GBQ661S)

- Consumer Price Index: Total All Items for the United Kingdom, Growth Rate Same Period Previous Year, Quarterly, Not Seasonally Adjusted (Series: CPALTT01GBQ659N)

- 3-Month or 90-day Rates and Yields: Treasury Securities for the United Kingdom, Percent, Quarterly, Not Seasonally Adjusted (Series: IR3TTS01GBQ156N)

Data for Canada:

- Source: St. Louis FRED Database

- Gross Domestic Product by Expenditure in Constant Prices: Total Gross Domestic Product for Canada, Index 2015=100, Quarterly, Seasonally Adjusted (Series: NAEXKP01CAQ661S)

- Consumer Price Index: Total All Items for Canada, Growth Rate Same Period Previous Year, Quarterly, Not Seasonally Adjusted (Series: CPALTT01CAQ659N)

- Interest Rates, Government Securities, Treasury Bills for Canada, Percent per Annum, Quarterly, Not Seasonally Adjusted (Series: INTGSTCAM193N) 
Appendix B: Sub-Sample Estimates of the FM-model

In this section we report parameter estimates for the FM-model for the pre and post-Volcker sub-samples.

B1. Pre-Volcker: 1961Q1-1979Q2

For our estimates of the models over the pre-Volcker period we calibrated the constant parameter in the measurement equation (9) as in Table 5

\begin{tabular}{cccc}
\hline \multicolumn{4}{c}{ Table 5: Calibration of intercept } \\
\hline \hline & United States & United Kingdom & Canada \\
\hline$c_{y}$ & 2.99 & 3.32 & 2.94 \\
\hline \hline
\end{tabular}

Table 6.A and 6.B report the posterior mean and $90 \%$ probability intervals for both the common and the country-specific model parameters, respectively.

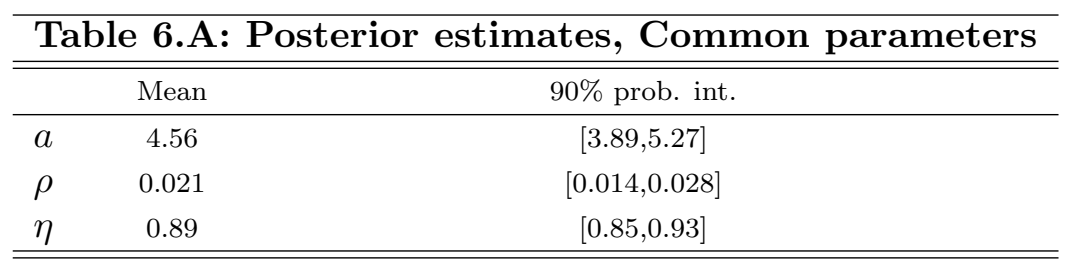

\begin{tabular}{lcc|cc|cc}
\hline \multicolumn{7}{c}{ Table 6.B: Posterior estimates, Country-specific } \\
\hline \hline \multicolumn{2}{c}{ United States } & \multicolumn{2}{c}{ United Kingdom } & \multicolumn{2}{c}{ Canada } \\
\hline $\bar{r}$ & 0.019 & {$[0.001,0.042]$} & 0.043 & {$[0.001,0.078]$} & 0.018 & {$[0.001,0.036]$} \\
$\rho_{R}$ & 0.95 & {$[0.92,0.98]$} & 0.89 & {$[0.82,0.95]$} & 0.91 & {$[0.86,0.97]$} \\
$\lambda$ & 2.43 & {$[1.67,3.18]$} & 1.19 & {$[0.66,1.75]$} & 1.28 & {$[0.71,1.86]$} \\
$\mu$ & 0.59 & {$[0.34,0.81]$} & 0.68 & {$[0.42,0.97]$} & 0.49 & {$[0.26,0.71]$} \\
\hline$g_{y}$ & 0.010 & {$[0.008,0.011]$} & 0.008 & {$[0.006,0.009]$} & 0.011 & {$[0.010,0.012]$} \\
$\rho_{d}$ & 0.75 & {$[0.69,0.82]$} & 0.84 & {$[0.76,0.93]$} & 0.82 & {$[0.75,0.90]$} \\
$\rho_{s}$ & 0.95 & {$[0.92,0.98]$} & 0.88 & {$[0.79,0.97]$} & 0.84 & {$[0.74,0.94]$} \\
\hline$\sigma_{R}$ & 0.006 & {$[0.005,0.007]$} & 0.009 & {$[0.008,0.011]$} & 0.006 & {$[0.005,0.007]$} \\
$\sigma_{d}$ & 0.013 & {$[0.010,0.016]$} & 0.013 & {$[0.009,0.018]$} & 0.010 & {$[0.007,0.013]$} \\
$\sigma_{s}$ & 0.092 & {$[0.059,0.125]$} & 0.078 & {$[0.054,0.103]$} & 0.069 & {$[0.050,0.088]$} \\
$\sigma_{\eta_{2}}$ & 0.004 & {$[0.003,0.005]$} & 0.017 & {$[0.014,0.019]$} & 0.007 & {$[0.006,0.008]$} \\
\hline$\rho_{R, \eta_{2}}$ & -0.17 & {$[-0.38,0.07]$} & -0.01 & {$[-0.28,0.28]$} & -0.07 & {$[-0.34,0.22]$} \\
$\rho_{s, \eta_{2}}$ & 0.72 & {$[0.46,0.99]$} & 0.71 & {$[0.49,0.94]$} & 0.01 & {$[-0.57,0.53]$} \\
$\rho_{d, \eta_{2}}$ & 0.18 & {$[-0.11,0.44]$} & -0.18 & {$[-0.42,0.09]$} & 0.19 & {$[-0.03,0.44]$} \\
\hline \hline
\end{tabular}




\section{B2. Post-Volcker: 1983Q1-2007Q4}

We estimate the constrained version of the FM-model over the Post-Volcker period. We calibrate the constant parameter in the measurement equation (9) as in Table 7

\begin{tabular}{cccc}
\hline \multicolumn{4}{c}{ Table 7: Calibration of intercept parameter $c_{y}$} \\
\hline \hline & United States & United Kingdom & Canada \\
\hline$c_{y}$ & 3.72 & 3.85 & 3.80 \\
\hline \hline
\end{tabular}

Table 8.A and 8.B report the posterior mean and $90 \%$ probability interval for both the common and the country-specific model parameters, respectively.

\begin{tabular}{ccc}
\hline \multicolumn{3}{c}{ Table 8.A: Posterior estimates, Common parameters } \\
\hline \hline & Mean & $90 \%$ prob. int. \\
\hline & 5.63 & {$[5.10,6.12]$} \\
$\eta$ & 0.018 & {$[0.011,0.024]$} \\
\hline \hline
\end{tabular}

Table 8.B: Posterior estimates, Country-specific

\begin{tabular}{lcc|cc|cc}
\hline \hline & \multicolumn{2}{c|}{ United States } & \multicolumn{2}{|c|}{ United Kingdom } & \multicolumn{2}{c}{ Canada } \\
\hline & Mean & $90 \%$ prob. int. & Mean & $90 \%$ prob. int. & Mean & $90 \%$ prob. int. \\
\hline $\bar{r}$ & 0.084 & {$[0.060,0.010]$} & 0.047 & {$[0.016,0.081]$} & 0.082 & {$[0.057,0.100]$} \\
$\rho_{R}$ & 0.89 & {$[0.84,0.93]$} & 0.95 & {$[0.93,0.97]$} & 0.97 & {$[0.95,0.99]$} \\
$\lambda$ & 1.95 & {$[1.46,2.38]$} & 2.46 & {$[1.90,3.00]$} & 1.66 & {$[1.14,2.11]$} \\
$\mu$ & 0.23 & {$[0.16,0.31]$} & 0.66 & {$[0.46,0.85]$} & 0.65 & {$[0.43,0.85]$} \\
\hline$g_{y}$ & 0.006 & {$[0.005,0.007]$} & 0.004 & {$[0.003,0.005]$} & 0.004 & {$[0.003,0.005]$} \\
$\rho_{d}$ & 0.75 & {$[0.67,0.82]$} & 0.82 & {$[0.77,0.87]$} & 0.83 & {$[0.78,0.89]$} \\
$\rho_{s}$ & 0.82 & {$[0.77,0.90]$} & 0.95 & {$[0.91,0.99]$} & 0.92 & {$[0.88,0.97]$} \\
\hline$\sigma_{R}$ & 0.004 & {$[0.003,0.005]$} & 0.008 & {$[0.007,0.008]$} & 0.007 & {$[0.006,0.007]$} \\
$\sigma_{d}$ & 0.010 & {$[0.008,0.013]$} & 0.008 & {$[0.006,0.010]$} & 0.007 & {$[0.005,0.009]$} \\
$\sigma_{s}$ & 0.088 & {$[0.067,0.110]$} & 0.064 & {$[0.050,0.080]$} & 0.080 & {$[0.055,0.105]$} \\
$\sigma_{\eta_{2}}$ & 0.006 & {$[0.005,0.007]$} & 0.006 & {$[0.005,0.007]$} & 0.007 & {$[0.006,0.008]$} \\
\hline$\rho_{R, \eta_{2}}$ & -0.14 & {$[-0.42,0.15]$} & 0.10 & {$[-0.17,0.39]$} & 0.08 & {$[-0.10,0.26]$} \\
$\rho_{s, \eta_{2}}$ & 0.29 & {$[-0.04,0.63]$} & 0.70 & {$[0.42,0.99]$} & 0.66 & {$[0.36,0.96]$} \\
$\rho_{d, \eta_{2}}$ & 0.30 & {$[0.14,0.44]$} & -0.08 & {$[-0.13,0.29]$} & -0.16 & {$[-0.33,0.01]$} \\
\hline \hline
\end{tabular}

